\title{
The distribution of presumptive thoracic paraganglionic tissue in the common marmoset (Callithrix jacchus)
}

J.A. Clarke and M. de B. Daly ${ }^{\dagger}$
Department of Physiology, Royal Free and University College Medical School, London, UK

\section{Correspondence \\ J.A. Clarke \\ Department of Physiology \\ Royal Free and University College \\ Medical School \\ Royal Free Campus \\ Rowland Hill Street \\ London, NW3 2PF \\ UK \\ Fax: +44-020-7472-6476 \\ E-mail: f.leitao@ rfc.ucl.ac.uk}

Research supported by the Welcome

Trust.

†Deceased March 1, 2002

Received October 9, 2001

Accepted February 6, 2002

\section{Abstract}

The aortic-pulmonary regions (APR) of seven adult marmosets (Callithrix jacchus) and the region of the right subclavian artery of a further three marmosets were diffusion-fixed with $10 \%$ buffered formol-saline solution. In both regions serial 5- $\mu \mathrm{m}$ sections were cut and stained by the Martius yellow, brilliant crystal scarlet and soluble blue method. Presumptive thoracic paraganglionic (PTP) tissue was only observed in the APR. PTP tissue was composed of small groups of cells that varied in size and number. The distribution of the groups of cells was extremely variable, so much so that it would be misleading to attempt to classify their position; they were not circumscribed by a connective tissue capsule, but were always related to the thoracic branches of the left vagus nerve. The cells lay in loose areolar tissue characteristic of this part of the mediastinum and received their blood supply from small adjacent connective tissue arterioles. Unlike the paraganglionic tissue found in the carotid body the cells in the thorax did not appear to have a profuse capillary blood supply. There was, however, a close cellular-neural relationship. The cells, 10-15 $\mu \mathrm{m}$ in diameter, were oval or rounded in appearance and possessed a central nucleus and clear cytoplasm. No evidence was found that these cells possessed a 'companion' cell reminiscent of the arrangement of type 1 and type 2 cells in the carotid body. In conclusion, we found evidence of presumed paraganglionic tissue in the APR of the marmoset which, however, did not show the characteristic histological features of the aortic body chemoreceptors that have been described in some non-primate mammals. A survey of the mediastina of other nonhuman primates is required to establish whether this finding is atypical for these animals.

\section{Introduction}

As far as we are aware, only Krahl (1) has made observations on paraganglionic tissue in the mediastinum of a non-human primate. In chimpanzees he described small masses of glomus tissue alongside the adventitia of the dorsal aspect of the bifurcation of the

\author{
Key words \\ - Presumptive paraganglionic \\ cells \\ - Thorax \\ - Marmoset
}

pulmonary trunk. He emphasised that this "glomus pulmonale" was not situated between the aortic and pulmonary trunks, but dorsal to the pulmonary trunk immediately before it branches. In Krahl's study the principal blood supply to the "glomus pulmonale" was traced in serial sections to its origin from the pulmonary trunk. Similar observa- 
tions were made by him in humans, cats and cows (1). This raised the possibility that chemoreceptors existed in the mediastinum that responded to changes in the partial pressures of oxygen $\left(\mathrm{PaO}_{2}\right)$ and carbon dioxide $\left(\mathrm{PaCO}_{2}\right)$ and $\mathrm{pH}$ of mixed venous blood and that the "glomus pulmonale" may have contributed to the hyperpnea of muscular exercise. However, the idea received little support; numerous other workers have failed to identify a pulmonary blood supply to glomus tissue in the mediastinum of adult non-primate animals (2-6).

The aim of the present study was to reexamine the problem as to whether thoracic paraganglionic tissue exists in a non-human primate. The common marmoset (Callithrix jacchus) was used and serial sections of the mediastinum were examined in the area occupied by the aorta, pulmonary trunk and hilus of the left lung, and origin of the left subclavian artery. Since the functions of the groups of cells to be described are not known, they will be referred to as presumptive thoracic paraganglionic (PTP) cells (7). At present there is doubt as to whether the established physiological role of the aortic bodies and perhaps subclavian bodies in some non-primate species such as the cat and dog can be applied to primates, including man, in which the distribution of such chemoreceptor tissue is unknown. Thus, we hoped that the outcome of this study would help to resolve the question of the exact distribution of this tissue in a non-human primate model that would be suitable for physiological investigation at a future date.

\section{Material and Methods}

All experiments were carried out in accordance with UK legislation governing experiments on animals. We would emphasise that we encountered some difficulty in obtaining suitable material specifically for this study in that the nature of some of the material investigated has perforce to be part of another study which has a minimal effect on the interpretation of our results. This also explains the relatively small numbers of animals studied. Mediastinal tissue from the marmosets was examined at two distinct sites: the aortic-pulmonary region and the area surrounding the origin of the right subclavian artery.

\section{Marmoset: aortic-pulmonary region}

This part of the mediastinal region was examined in two adult male common marmosets (Callithrix jacchus) weighing 370 and $385 \mathrm{~g}$, respectively (Table 1). In addition, five marmosets of either sex, weighing 309-338 g, were used which had been pretreated with MPTP (1-methyl-4-phenyl1,2,3,6-tetrahydropyridine; 8) as part of a parallel study. MPTP is a dopamine neurotoxic agent which is selective for neurones in the substantia nigra. All animals were anesthetized with sodium pentobarbitone (Sagatal, Rhöne Merieux, Harlow, Essex, UK), $50 \mathrm{mg} / \mathrm{kg}$ intraperitoneally and then decapitated. The chest was opened by a median sternotomy, and an injection of $10 \mathrm{ml}$ of 0.1 $\mathrm{M}$ sodium phosphate in a sodium chloride solution (154 $\mathrm{mM} \mathrm{Na}^{+}$) was made into the systemic circulation via the left ventricle. Blood and injected fluid were allowed to escape freely from a large incision in the right atrium. After death, the thoracic viscera were removed.

The excised mediastinal tissue was then carefully trimmed. The bronchial tree was removed to prevent the hyaline cartilage from interfering with the serial histological sectioning. This left a specimen consisting of the aortic-pulmonary septum, pulmonary bifurcation and vascular structures related to the hilus of the left lung, aorta and the origin of the left subclavian artery. It must be emphasised that during the dissection, the mediastinal connective tissue adjacent to these various vascular structures was not disturbed in order to preserve the natural 
habitat of paraganglionic tissues (Figures 1 and 2). The tissues were then fixed in $10 \%$ buffered formol-saline solution (the classical solution used for routine histopathological investigations) within 20 min from death for $48 \mathrm{~h}$, prepared routinely for light microscopy, and embedded in paraffin wax (British Drug Houses, Ltd./VWR International Ltda., Lutterworth, UK) at $56^{\circ} \mathrm{C}$. Ribbons of parasagittal serial $5-\mu \mathrm{m}$ sections were cut and mounted on glass. Every 20th section (i.e., at intervals of $100 \mu \mathrm{m}$ ) was stained using the one-stage MSB method (Martius yellow, brilliant crystal scarlet and soluble blue; 9) with Harris hematoxylin and eosin counterstain. Identification of PTP tissue in a section, together with subsequent staining of adjacent sections from the serial section series where paraganglionic tissue had been found, provided a complete picture of the distribution of such paraganglionic cells.

\section{Marmoset: origin of right subclavian artery}

A further three marmosets of either sex, weighing 340,368 and $385 \mathrm{~g}$, had been culled for husbandry reasons. The region of the right subclavian artery was exposed immediately after death and the clavicles, manubrium and strap muscles of the neck were removed. The first rib and origin of the right subclavian artery were identified. The first part of the right subclavian artery was removed, particular care being taken not to disturb perivascular connective tissues which might contain PTP tissue. The material was prepared, sectioned and stained as described above.

As pointed out in the Introduction, the distribution of non-primate thoracic chemoreceptor tissue is, at least in some species, well established (e.g., in Felix domesticus) and for this reason the present study included a confirmatory examination of such tissues in one cat (Felix domesticus), about 6 months of age, male sex and $2.6 \mathrm{~kg}$ body weight. Again, the material was prepared, sectioned and stained as described above.

\section{Results}

\section{Marmoset: aortic-pulmonary region}

Serial sections were cut in a parasagittal plane, starting at the left pulmonary hilus and cutting towards the median plane (Figures 1 and 2), so as to observe the relationship of PTP tissue to the complex arrange-
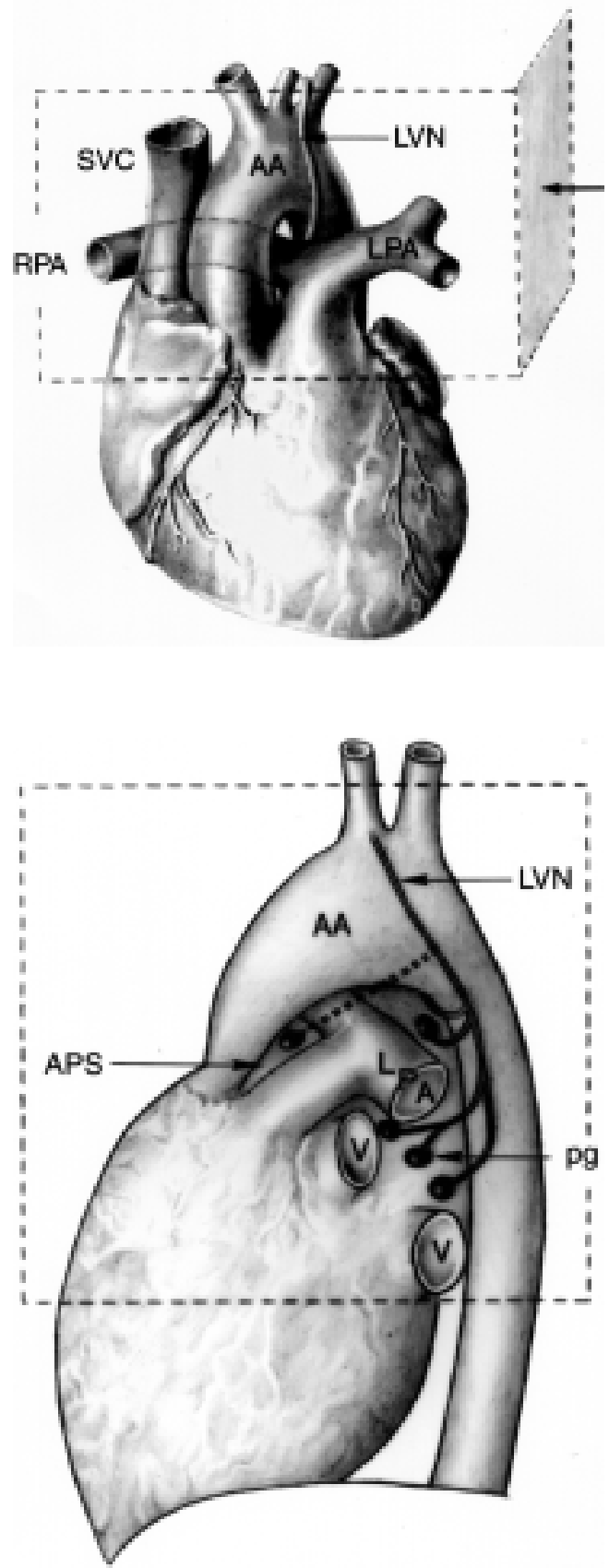

Figure 1. Ventral view of the marmoset heart showing the area removed (broken lines) for histological preparation. AA, aortic arch; LVN, left vagus nerve; RPA, LPA, right and left pulmonary arteries, respectively; SVC, superior vena cava. Pulmonary veins were omitted. The arrow denotes the parasagittal plane of sectioning.

Figure 2. Marmoset mediastinum viewed from the left side showing the area removed (broken lines) for histological preparation. The left bronchus was removed. APS, aortic-pulmonary septum; V, pulmonary veins; pg (filled circles), sites for presumptive paraganglionic cells. Doublebroken line from the left vagus indicates presumptive nerve supply to pg cells in APS. For other abbreviations, see legend to Figure 1 . This lateral view of the aortic arch results in the absence of the brachiocephalic trunk and gives a false impression of the shape of the arch itself. 
ment of extrahilar left pulmonary vessels lying normal to the plane of section.

Examination of the serial sections from the mediastina of all seven marmoset monkeys showed that the distribution of PTP tissue was extremely variable. Indeed the distribution was such that it would be mis-

\begin{tabular}{|c|c|c|c|c|c|}
\hline \multirow[b]{3}{*}{ No. } & \multirow{2}{*}{\multicolumn{2}{|c|}{ Animal }} & \multicolumn{3}{|c|}{ Discrete islands of PTP tissue } \\
\hline & & & \multicolumn{2}{|r|}{ APR } & \multirow{2}{*}{$\frac{\mathrm{LSA}}{\text { No }}$} \\
\hline & Sex & Weight (g) & No. & Size $(\mu \mathrm{m})$ & \\
\hline 1 & $M$ & 370 & 1 & 100 & 0 \\
\hline 2 & $M$ & 385 & 4 & $100,200,50,150$ & 0 \\
\hline 3 & $M$ & 312 & 2 & 500,200 & 0 \\
\hline 4 & $M$ & 328 & 4 & $300,50,50,50$ & 0 \\
\hline 5 & $\mathrm{~F}$ & 338 & 4 & $150,50,50$ & 0 \\
\hline 6 & $\mathrm{~F}$ & 309 & 2 & 100,300 & 0 \\
\hline 7 & $M$ & 314 & 2 & 50,100 & 0 \\
\hline
\end{tabular}

Animals 1 and 2 were untreated controls; animals 3-7 treated with MPTP, a dopamine neurotoxic agent, as part of a parallel study (see Methods). APR, aortic-pulmonary region; LSA, left subclavian artery.

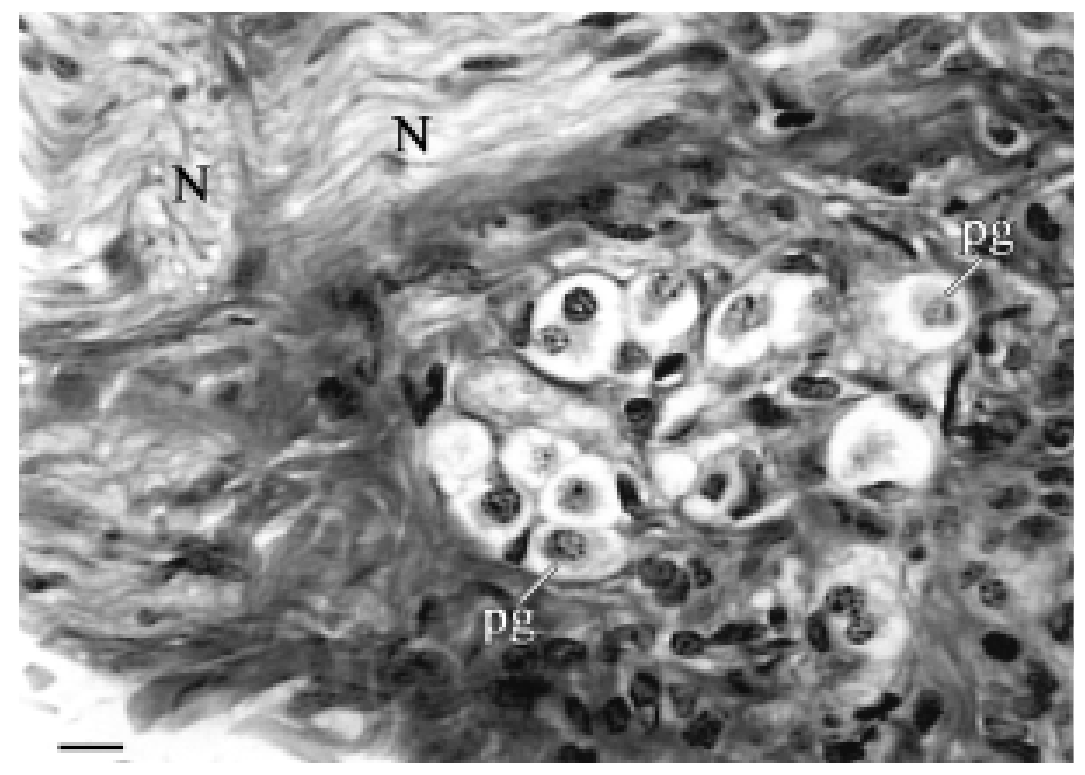

Figure 3. Photomicrograph of mediastinal paraganglionic tissue stained by the Martius scarlet, blue method. Collection of small clear presumptive paraganglionic (pg) cells lying in the mediastinal connective tissues adjacent to a small vein (not shown). $N$, branch of the left vagus nerve. Bar, $20 \mu \mathrm{m}$. leading to attempt to classify its position in terms only related to mediastinal vessels. It would be more satisfactory to record that mediastinal PTP tissue may be found mainly in close proximity to small terminal perivascular branches of the left vagus nerve. Such an approach conveniently overcomes two problems previously encountered by some authors $(5,6,10)$, who regarded it as definitive chemoreceptor tissue: firstly, it provided a means for considering the tissue's function in relation to its intrinsic cellular arrangement, and secondly, it overcame the problem of describing the position of a tissue, inconstant in its own distribution, in an area where the vascular arrangements may be dissimilar within the same species and certainly so between different species.

Typically, the thoracic paraganglionic tissue was composed of small groups of cells and the size, number, and distribution of these groups varied in all seven marmosets (Table 1). In all the animals the groups of cells were always related to branches of the left vagus nerve, irrespective of their position in the mediastinum. The distribution of all groups of paraganglionic cells in the seven animals is shown in Figure 2.

The cells of PTP tissue did not have an independent arterial supply in any animal. Moreover, in contrast to the PTP tissue found in the carotid bodies (7), the cells were not circumscribed by a connective tissue capsule. Instead, these mediastinal cells lay in loose areolar tissue characteristic of this part of the thorax (Figure 3) and received their blood supply from small adjacent connective tissue arterioles which did not originate from any part of the course of the pulmonary arteries or other identifiable stem vessels. Although our material was of necessity diffusion-fixed (see Methods), the cells in the thorax, unlike the carotid body, did not appear to have a profuse capillary supply. In some sections groups of cells comprising paraganglionic tissue were associated with a small vein (Figure 4) and individual cells 
even lay in close association with venous endothelium (Figure 4). In all the animals, a small nerve branched out around groups of these mediastinal cells and in some sections cells were interspersed along the path of the nerve (Figure 5). This neural arrangement occurred irrespective of the size and mediastinal position of the PTP tissue, and particularly applied to cells observed in the aorticpulmonary septum and in a periadventitial position adjacent to the aortic arch. Unfortunately, the limitations of light microscopy excluded a detailed description of the cellular-neural relationship.

The appearance of the cells in the groups of PTP tissue was similar by light microscopic standards in all the animals. Each cell was oval or rounded in appearance, had a diameter between 10-15 $\mu \mathrm{m}$ and possessed a central nucleus and clear cytoplasm. The clear appearance of the cytoplasm in these cells in the thorax contrasted sharply with the orange-red tinctorial appearance of type 1 cells we have observed in the primate carotid body (11) and the carotid body of other non-primate species $(12,13)$ using an identical MSB stain. In all the serial sections examined none of the cells in thoracic paraganglionic tissue possessed a 'companion' cell reminiscent of the arrangement of type 1 and type 2 cells found in the carotid body. In the larger arrangements of paraganglionic tissue a fine matrix of mediastinal connective tissue embraced the cells so that to the casual observer fibroblast nuclei might be mistaken for 'type 2-like' cell nuclei. A more careful examination of the tissue in many sections revealed that such an arrangement did not exist.

\section{Marmoset: origin of left subclavian artery}

With reference to Figure 2, it was possible to examine in all seven animals the perivascular tissues in the region of the origin of the left subclavian artery. No PTP tissue was found (Table 1).

\section{Cat (Felix domesticus)}

A similar study of thoracic paraganglionic tissue was made in one animal for comparison because of the known presence of aortic body chemoreceptors $(4,5,10,14)$. Two morphologically different groups of cells were found. One group of cells had morpho-

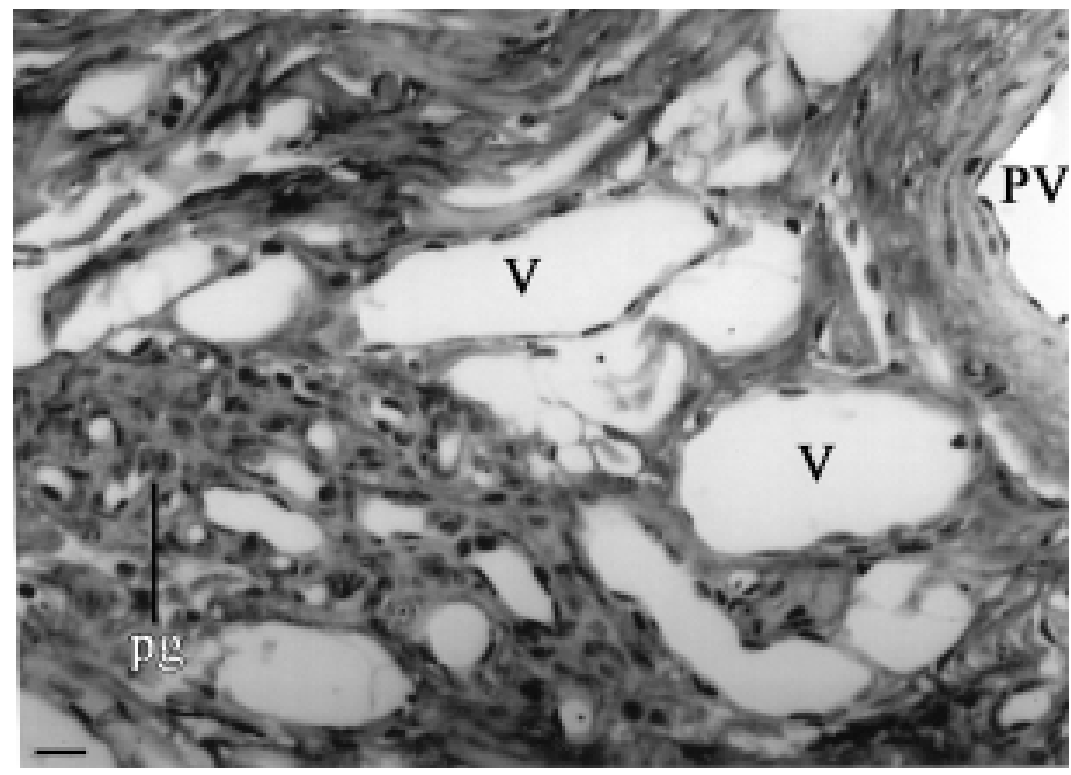

Figure 4. Collection of small clear paraganglionic $(\mathrm{pg})$ cells lying adjacent to small veins $(\mathrm{V})$ in the mediastinal connective tissues. PV, small extra-hilar pulmonary vein. Bar, $20 \mu \mathrm{m}$.

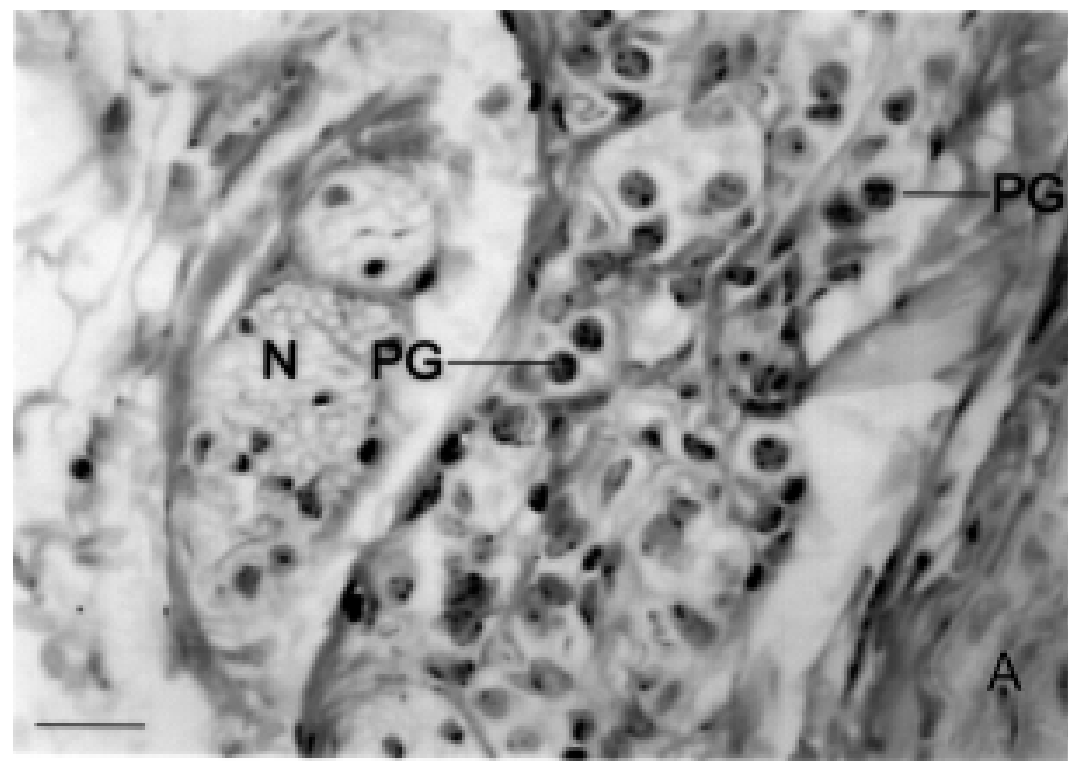

Figure 5. Small clear paraganglionic (PG) cells scattered in the course of a branch of the left vagus nerve $(\mathrm{N})$ lying adjacent to the aortic wall $(\mathrm{A})$. Bar, $50 \mu \mathrm{m}$. 
logical features similar to the paraganglionic cells described above for the marmoset (Figure 6A), and the second group showed characteristics typical of "aortic body chemoreceptors" consisting of both type 1 and type 2 cells (Figure 6B). It is to be noted that neither the mediastinal small clear cells in the cat
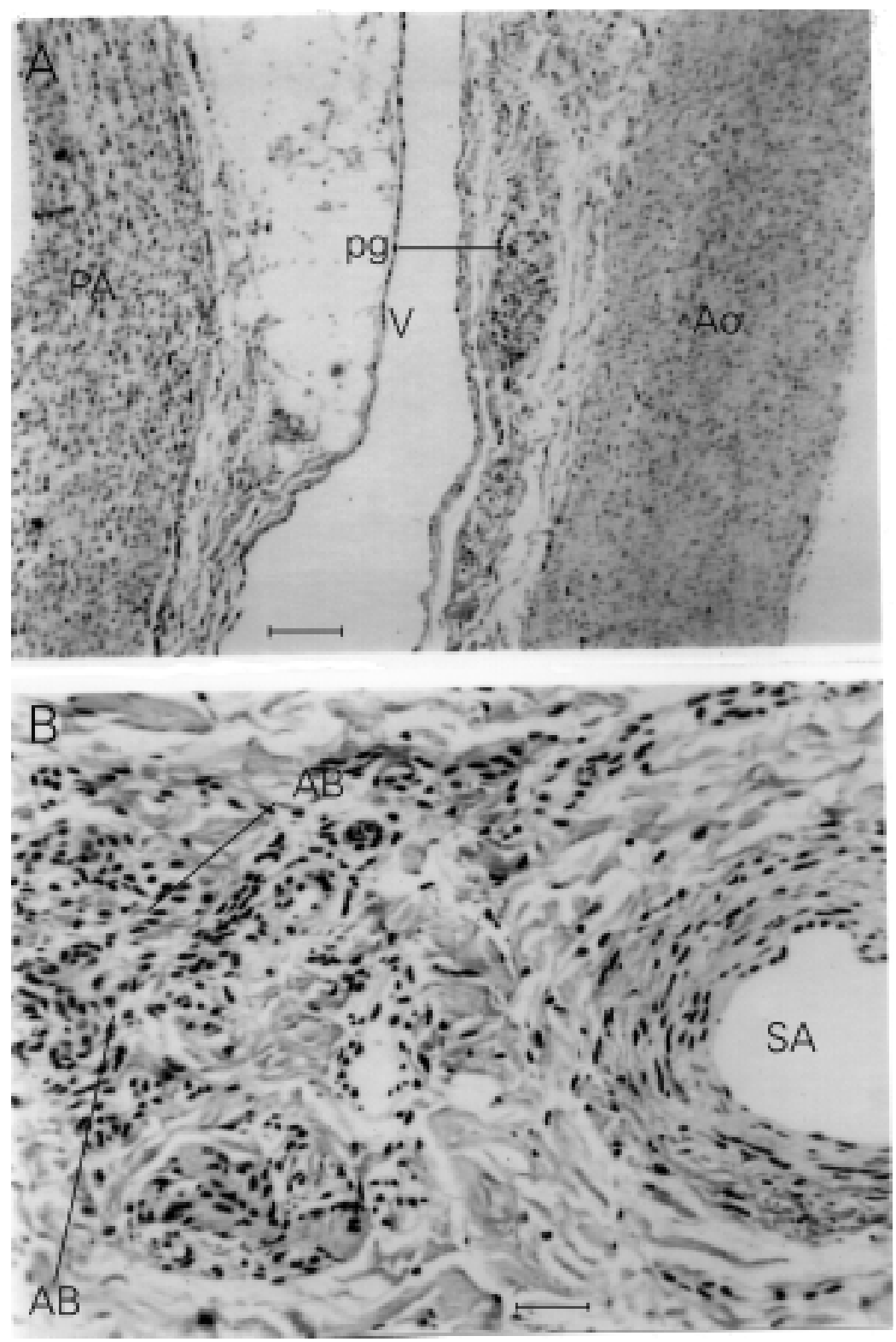

Figure 6. Comparison of small clear presumptive paraganglionic cells and a classical aortic body in the cat. A, Shows a group of small clear paraganglionic (pg) cells lying adjacent to a systemic vein $(\mathrm{V})$ and aortic wall (Ao) in the aortic-pulmonary septum. PA, pulmonary artery. Bar, $200 \mu \mathrm{m}$. B, An aortic body (AB) and a stem artery (SA) from an adjacent connective tissue artery. Bar, $50 \mu \mathrm{m}$. nor the type 1 cells of the cat's aortic bodies stained particularly well with the MSB stain.

\section{Marmoset: origin of right subclavian artery}

No paraganglionic cells were found in the perivascular tissues surrounding the origin of the right subclavian artery in any of the three animals studied.

\section{Discussion}

The original objective of the present study was to establish the distribution of aortic body chemoreceptor cells in a non-human primate, as a necessary preliminary to examining under controlled conditions their reflex control of the respiratory and cardiovascular systems. In fact the main finding of this study was somewhat surprising to us, since the small groups of paraganglionic cells found in the aortic-pulmonary region did not have classical characteristics associated with aortic body chemoreceptors in non-primate animals $(2,5,6,10,15-17$, and present paper). Furthermore, no such cells were found in the perivascular tissues in the regions of the origins of the left and right subclavian arteries.

Our findings have therefore presented a major problem as to the identity of these paraganglionic cells. On purely morphological grounds the association of the marmoset cells with branches of the left vagus nerve would suggest that they have a similar origin to other paraganglionic cells and that they are neural crest in origin. Our observation that cells with similar characteristics to those noted in the marmoset were also observed in close proximity to typical type 1 cells in aortic bodies of the cat lends support to their common origin from the neural crest. Further morphological comparisons between marmoset paraganglionic and aortic body type 1 cells only emphasised differences between the two populations of cells. For instance the groups of paraganglionic cells 
in the marmoset lacked a connective tissue capsule found in aortic bodies $(2,5,18)$; the marmoset cells received their blood supply from connective tissue arterioles rather than from a stem vessel $(2,10)$; the marmoset cells did not have the profuse capillary bed associated with chemoreceptor tissue, and there appeared to be an absence of type 2 cells in the animals we studied.

The clear cytoplasm associated with the marmoset mediastinal cells is probably an artefact due to diffusion-fixation. Unfortunately, we did not have sufficient freedom of access to the marmosets to prepare our material by the perfusion-fixation employed in our other studies (11-13). An ultrastructural study could probably demonstrate cytological characteristics shared with type 1 cells, but would be very difficult to carry out in view of the protean distribution of these cells. In the mediastina of non-primate animals collections of small clear cells have also been observed along the course of the left vagus nerve and described as being similar to small intensely fluorescent cells that are found in autonomic ganglia (19). The small clear cells we have observed are slightly larger than small intensely fluorescent cells.

It could be that the small clear paraganglionic cells are a morphological variant of the aortic bodies, as indeed there are structural differences between the aortic bodies and the carotid bodies (20). In that study the blood supply to the subclavian body of the rat was described as arising from arterioles rather than from stem vessels, as we have described for the groups of paraganglionic cells in the marmoset. In this connection it has been shown in another marmoset not included in this study that some of the type 1 cells in the aortic region showed a similar morphology to those in the aortic-pulmonary area and gave a positive staining reaction to tyrosine hydroxylase typical of cells in the carotid bodies (Clarke JA, unpublished observation). Furthermore, in the cat, not only groups of cells whose structure was similar to aortic body chemoreceptors have been described but also groups of paraganglionic cells that lay on the surface of the atria and base of the heart (epicardial) with a different structure (17). This latter group of cells, however, is outside the region covered in the present investigation. Thus, in a situation where the morphological identity of these small clear cells in the mediastina of marmosets is unclear, it would be premature to speculate on their exact function.

The results of physiological studies in some non-human primates (dog, cat), in which aortic chemoreceptors are abundant, indicate that this group of chemoreceptors differ quantitatively from those in the carotid bodies with respect to both their responses to specific stimuli and their reflex functions $(14,21)$. Consequently, it is no longer possible to consider them functioning as a single entity in the control of the respiratory and cardiovascular systems nor to apply the results of these studies to humans. Our present investigation revealing the apparent lack of classical aortic bodies in the marmoset which might have been a suitable species for subsequent appropriate physiological studies, could be atypical for other nonhuman primates. A survey of the mediastina of other primates would therefore appear to be required to establish the "thoracic chemoreceptor status" of these animals.

Turning now to the situation in humans, thoracic paraganglia structurally similar to those in the carotid bodies have been demonstrated (22-25), but knowledge of their functions is sparse. For obvious reasons it is not possible to carry out properly controlled experiments that would distinguish primary reflex responses evoked by hypoxia from secondary effects of other inputs to, or direct effects on the central nervous system or of changes in the secretion of suprarenal catecholamines. Whereas it has been established that the respiratory response to hypoxia is due entirely to stimulation of the carotid bodies, the aortic bodies playing a 
negligible role, there is, in our opinion, no unequivocal evidence for any role of the aortic bodies in the control of the cardiovascular system (21).

\section{Acknowledgments}

We wish to express our thanks to Dr. R.K.B. Pearce, Pharmacology Group, Biomedical Sciences Division, King's College London, to Drs. R.M. Baker and H.F. Baker,
Department of Experimental Psychology, Cambridge University for kindly supplying us with the specimens, and to Mr. Michael Jackson for technical assistance. We also thank Mrs. Beverley Wilson of the Department of Pathology, Addenbrooks Hospital, Cambridge, for her expert assistance in the histological preparation of the material, and Mr. C.F.J. Henn for his artistic contribution (Figures 1 and 2).

\section{References}

1. Krahl VE (1962). The glomus pulmonale: its location and microscopic anatomy. In: de Reuck AVS \& O'Connor M (Editors), Pulmonary Structure and Function. Ciba Foundation Symposium, Churchill, London, UK.

2. Nonidez J F (1935). The aortic (depressor) nerve and its associated epithelioid body, the glomus aorticum. American J oumal of Anatomy, 57: 259-301.

3. Knoche H \& Schmitt G (1963). Über chemo- und Pressoreceptorenfelder am Coronarkreislauf. Zeitschrift für Zellforschung und Mikroskopische Anatomie, 61: 524-560.

4. Verity MA, Hughes T \& Bevan J A (1964). Aortico-pulmonary glomus tissue distribution and blood supply in the adult cat. Science, 145: 172-173.

5. Coleridge HM, Coleridge J CG \& Howe A (1967). A search for pulmonary arterial chemoreceptors in the cat, with a comparison of the blood supply of the aortic bodies in the new-born and adult animal. J ournal of Physiology, 191: 353-374.

6. Coleridge HM, Coleridge J CG \& Howe A (1970). Thoracic chemoreceptors in the dog. A histological and physiological study of the location, innervation and blood supply of the aortic bodies. Circulation Research, 26: 235-247.

7. Böck P (1982). The Paraganglia. SpringerVerlag, Berlin, Germany.

8. Pearce RKB, J ackson $M$, Smith $L$, J enner P \& Marsden CD (1994). Chronic L-dopa administration induces dyskinesias in the MPTP-treated marmoset. British J ournal of Pharmacology, 112: 150P (Abstract).

9. Dawes RE \& Hillier MH (1964). A onestage technique for differentiating the al- pha and beta cells of the anterior pituitary. J ournal of Medical Laboratory Technology, 21: 62-63.

10. Howe A (1956). The vasculature of the aortic bodies in the cat. J ournal of Physiology, 134: 311-318.

11. Clarke J A, Daly M deB, Ead HW \& Kreclovic $G$ (1993). A morphological study of the size of the vascular compartment of the carotid body in a non-human primate (Cercopithicus ethiopus), and a comparison with the cat and rat. Acta Anatomica, 147: 240-247.

12. Clarke J A \& Daly MdeB (1981). Distribution of carotid body type-I cells and other periadventitial type-I cells in the carotid bifurcation regions of the rabbit. Cell and Tissue Research, 216: 603-614.

13. Clarke J A \& Daly M deB (1983). Distribution of carotid body type-I cells and other periadventitial type-I cells in the carotid bifurcation regions of the cat. Anatomy and Embryology, 166: 169-189.

14. Lahiri S (1991). Oxygen biology of peripheral chemoreceptors. In: Lahiri S, Cherniack NS \& Fitzgerald RS (Editors), Response and Adaptation to Hypoxia. American Physiological Society, New York, NY, USA, 95-106.

15. Muratori G (1935). Connessioni tra tessuto paragangliare e zone recettrici aortiche in vari mammiferi. Monitore Zoologico Italiano, 45: 300-310.

16. Nonidez J F (1937). Distribution of the aortic nerve fibers and the epithelioid bodies (supracardial 'paraganglia') in the dog. Anatomical Record, 69: 299-313.

17. Goormaghtigh $N \&$ Pannier R (1939). Les paraganglions du coeur et des zone vasosensibles carotidienne et cardio-aortique chez le chat adulte. Archives de Biologie, 50: 455-533.

18. McDonald DM \& Blewett RW (1981). Location and size of carotid body-like organs (paraganglia) revealed in rats by the permeability of blood vessels to Evans blue dye. J ournal of Neurocytology, 10: 607643.

19. Kummer W \& Neuhuber WL (1989). Vagal paraganglia of the rat. J oumal of Electron Microscopy, 12: 343-355.

20. Hansen JT (1981). Innervation of the rat aortic (subclavian) body: an ultrastructural study following axonal degeneration. J ournal of Ultrastructure Research, 74: 8394.

21. Daly MdeB (1997). Peripheral Arterial Chemoreceptors and Respiratory-Cardiovascular Integration. Monograph of the Physiological Society, No. 46. Clarendon Press, Oxford, UK.

22. Busacchi $P$ (1912). I corpi cromaffini del cuore umano. Parte prima. I corpi cromaffini del tronco arterioso. Archivio Italiano di Anatomia e di Embriologia, 11: 352376.

23. Penitschka W (1931). Paraganglion aorticum supracardiale. Zeitschrift für Mikroskopisch-Anatomische Forschung, 24: 2437.

24. Palme $F$ (1934). Die Paraganglien über dem Herzen und im Endigungsgebiet des Nervus depressor. Zeitschrift für Mikroskopisch-Anatomische Forschung, 36: 391420.

25. Lebona GT (1993). The presence of paraganglia in the human ascending aortic fold: histological and ultrastructural studies. J oumal of Anatomy, 183: 35-41. 